\title{
'Let us imagine that God has made a miniature earth and sky': Malebranche on the Body-Relativity of Visual Size
}

\begin{abstract}
Malebranche holds that visual experience represents the size of objects relative to the perceiver's body and does not represent objects as having intrinsic or nonrelational spatial magnitudes. I argue that Malebranche's case for this body-relative thesis is more sophisticated than other commentators-most notably, Atherton (I990) and Simmons (2003)-have presented it. Malebranche's central argument relies on the possibility of perceptual variation with respect to size. He uses two thought experiments to show that perceivers of different sizes-namely, miniature people, giants, and typical human beingscan experience the very same objects as having radically different sizes. Malebranche argues that there is no principled reason to privilege one of these ways of experiencing size over the others and, more specifically, that all three kinds of perceivers experience size veridically. From the possibility of this kind of veridical perceptual variation, Malebranche infers that visual experience represents only body-relative size.
\end{abstract}

KEYWORDS: Malebranche, contents of perception, spatial perception, scale, body-relativity

\section{Introduction}

Consider a perceiver looking at a palm tree. Her visual experience will represent the palm tree as having various properties: shape, location, color, and size. Let us focus on the last property on this list. What kind of property does the perceiver's visual experience of size attribute to the palm tree? Malebranche's answer to this question is that the perceiver's visual experience represents only that the palm tree is bigger than she is. Her visual experience does not, according to Malebranche, represent the palm tree as having any absolute, intrinsic, or nonrelational spatial

An earlier version of this paper was presented at the panel on 'Active Embodied Thinking in Early Modern Philosophy' organized by Lisa Shapiro at the meeting of the Canadian Philosophical Association in Vancouver, spring 20I9. I am grateful to my fellow panelists and the audience at this event for their many helpful criticisms and suggestions. I would also like to thank the members of my graduate seminar in fall 2018 for working through this material with me, and especially Arthur Krieger for his trenchant objections to my reading of Malebranche. I also owe a special debt of gratitude to many friends and colleagues for help along the way, for illuminating discussion and extensive written comments: Lee-Ann Chae, Eugene Chislenko, Becko Copenhaver, Andrew Hamilton, Marcy Lascano, Elliot Paul, Alison Peterman, and Lisa Shapiro. A special thanks goes to Alison Simmons for showing me the way into Malebranche's miniature and giant worlds. 
magnitude. More generally, Malebranche holds that the visual experience of size represents only the body-relative sizes of things, or their size-in-relation-to-us. As Malebranche writes in the Search After Truth (hereafter Search), 'our sight does not represent extension to us as it is in itself, but only as it is in relation to our body' (Malebranche I958: I: 84 [hereinafter cited as OC by volume and page] and Malebranche I997a: 28 [hereinafter cited as LO by page], emphasis added). Many commentators-such as Gueroult (I959: 57-58), Rome (I963: 287-99), Watson (I966: 43-44), Alquié (I974: I74), McCracken (I983: 26 and 74), Atherton (I990: I3 I-32), Moriarty (2003: I 59), Simmons (2003: 400-40I), and Chamberlain (2020)—recognize that Malebranche accepts this phenomenological thesis. But they have not got to the bottom of his reasons for accepting it. I argue that Malebranche's main argument for his body-relative view is more sophisticated and plausible than other commentators-most notably, Atherton (I990) and Simmons (2003) - have recognized.

Malebranche uses two thought experiments to show that perceivers of different sizes-namely, miniature people, giants, and typical human beings-can experience the very same objects as having radically different sizes. Atherton (I990: I32) reads Malebranche as arguing directly from the possibility of this kind of perceptual variation to the conclusion that visual experience represents the size of objects relative to the perceiver's body. I argue that Atherton's reconstruction of the argument goes too fast. Simmons (2003: 402) suggests one way of filling in the details: she interprets Malebranche as holding that the best explanation for experienced perceptual variation is that visual perception tracks body-relative size. There are two problems with Simmons's reconstruction, however. One is that Simmons's interpretation requires that visual experiences represent the properties they track or covary with; yet, Malebranche generally rejects this presupposition. The other is that her reconstruction omits a premise that Malebranche suggests is crucial: namely, that there is no principled reason to privilege one of these ways of seeing size-namely, the miniature person's, the giant's, or the typical human being's-over the others. I defend a reconstruction that incorporates this crucial premise. On my reading, Malebranche argues that the differently sized perceivers can see the same objects as having different sizes without being subject to any illusion, and the best explanation for this variation without illusion is that their respective visual experiences represent only body-relative size.

\section{Preliminaries}

To clarify what I mean by visual experience, consider, again, our perceiver looking at the palm tree. Malebranche offers a mechanistic account of the palm tree's stimulation of the perceiver's visual system and the resulting motions in her nerves and brain, in terms of the 'pulse and the motion' of insensible particles and the 'agitation of the fibers' of her body (OC I: I29/LO: 52). He then introduces a psycho-physiological law, which he calls 'the law of the union', connecting states of the brain with sensory states of the perceiver's soul. Changes in the brain give rise to 'the passion, the sensation, or the perception of the soul, i.e. what each of 
us senses in spite of himself' (OC I: I 29-30/LO: 52). When the perceiver looks at the palm tree, the law of the union coordinates motions in her brain with a kaleidoscope of green, yellow, gray, and brown sensations. These sensations form a two-dimensional array of color patches, corresponding to the pattern of retinal stimulation (OC I: 96-97/LO: 34). A host of natural judgments, which 'occur in us and independently of us, and even in spite of us', supplements these color sensations (OC I: II9-I20/LO: 46). Natural judgments explain the perceiver's visual experience as of three-dimensional objects and are responsible for much of the information sight conveys to the perceiver's conscious point of view. I use the terms 'visual experience' and 'visual perception' to refer to the overall conscious result of combining sensations and natural judgments.

Malebranche's use of the term 'natural judgment' can be misleading insofar as 'judgment' suggests a nonsensory or belief-like state. For Malebranche, however, natural judgments are operations of the senses, as much a product of the law of the union as the perceiver's sensations: 'as the senses can only sense and never judge, properly speaking, it is certain that this natural judgment is only a compound sensation that can consequently be mistaken' (OC I: 97/LO: 34). He reiterates that 'natural judgment is only a sensation' (OC I: I3O/LO: 52; see also OC I: II9-20/LO: 46-47, OC I: I 56-58/LO: 68-69, and OC XV: I7). Malebranche uses the term 'free judgment' to refer to a person's beliefs or commitments. Free judgment is 'a judgment of the will, which can be avoided, and which consequently we must not make if we wish to avoid error' (OC I: I 56/LO: 68). We almost always believe what we see: 'sensation or natural judgment is almost always followed by another, free judgment that the soul makes so habitually that it is almost unable to avoid it' (OC I: I3O/LO: 52). But Malebranche insists that seeing and believing are different kinds of mental states, with different relations to the will.

Scholars disagree about whether sensible quality sensations-like a sensation of red-are representational and/or intentional for Malebranche. Rodis-Lewis (I963: I03 and I39), Alquié (I974: 505), Nadler (I992: I99), Jolley (I995: I3I), and Schmaltz (I996: 99 and I07-I08), for example, argue that Malebranchean sensations are not intentional. Radner (I978), Reid (2003: 584), and Simmons (2009) argue that they are. This debate is orthogonal to whether a person's overall visual experience-i.e., the conscious result of combining sensations and natural judgments-is representational. Regardless of what he might think about sensations, Malebranche clearly holds that visual experience takes a stand on the existence of objects and their properties in the perceiver's vicinity and, hence, has representational content. Malebranche endorses this view when he refers to the 'testimony' or 'reports' of the senses (OC XII: 30 and Malebranche I997b: 4 [hereinafter cited as JS]) and when he claims that the senses 'speak' (OC I: I6/LO: xxxvii, OC X: I I3), 'represent' (OC I: I77-78/LO: 79-80), 'inform us' (OC I: 92/ LO: 32), and are 'witnesses' (OC XI: I33 and OC XII: Ioo/JS: 62). If the senses speak or testify to us, then we can ask whether they speak veridically or not and, more generally, what the world would have to be like for their testimony to be true.

Malebranche sometimes suggests that error belongs uniquely to the will rather than visual experience or, in other words, that error attaches to free rather than 
natural judgments. In the Search, Malebranche writes that 'properly speaking only the misuse of freedom is the cause of error' (OC I: 65/LO: I6), that 'we are deceived not by our senses but by our will, through its precipitous [free] judgments' (OC I: 77/LO: 23), and that 'error consists only in the hasty consent of the will' (OC II: 250/LO: 4II; see also OC I: I60/LO: 69-70). Malebranche's point is that perceivers are not at fault or to blame for undergoing an illusory or nonveridical visual experience. Visual experiences 'occur in us and independently of us, and even in spite of us,' and so we do not err when our visual systems misfire (OC I: II9-I 20/LO: 46). Rather, perceivers are only at fault when they freely make a judgment that they should not, for example, when one gives the 'hasty consent of one's will' to a visual experience without considering the matter carefully (ibid.). Similarly, perceivers are not to be praised or credited for their veridical experiences either; they should only be praised for freely judging well.

Thus, Malebranche distinguishes (i) whether a visual experience is veridical, that is, whether the world is the way visual experience represents it as being, and (ii) whether a subject has exercised his or her will correctly in response to his or her visual experience. The latter kind of evaluation redounds upon the perceiver; the former does not. I will use the terms 'nonveridicality' and 'misrepresentation' to refer to failures at the level of visual experience, whereas I will follow Malebranche in using the term 'error' for failures of the will. Admittedly, Malebranche sometimes refers to 'the errors of the senses' (OC I: 68/LO: I7 and OC I: IоI/LO: 37) and describes the senses as 'deceiving' us (OC I: 79/LO: 25, OC I: I76/LO: 79). But Malebranche is speaking loosely in these passages. The so-called 'errors of the senses' are occasions for error, rather than errors strictly speaking (OC I: 65/LO: I6).

\section{The Body-Relativity of Visual Size}

Malebranche holds that visual experience does not acquaint us with what he refers to as 'extension in itself [étendue en soi], 'true' or 'absolute size,' terms he uses more or less interchangeably. In the chapter of the Search devoted to size perception, he writes that 'our sight does not represent extension to us as it is in itself [l'étendue, selon ce qu'elle est en elle-même]' (OC I: $84 / \mathrm{LO}: 28$, emphasis added), that 'it is a prejudice grounded in no reason at all to believe that one sees bodies as they are in themselves [les corps tells qu'ils sont en eux-mêmes]' (OC I: 87/LO: 29), and that 'our eyes deceive us . . . with regard to the size of bodies in themselves [des corps en eux-mêmes]' (OC I: 93/LO: 32). He also claims that 'we do not know how to determine the absolute size [la grandeur absolue] of the bodies surrounding us' (OC I: 86/LO: 28) and that 'we are quite uncertain of the true size of the bodies we see' (OC I: 88/LO: 30). In general, Malebranche holds that 'our senses . . . cannot tell us what bodies are in themselves', from which it follows that sight in particular cannot tell us about the size of bodies in themselves (OC I: I 86/LO: 85 ). These passages raise two interpretive questions. First, what kind of property is Malebranche talking about when he refers to 'extension in itself', 'true' or 'absolute size'? And second, what kind of access to this property does Malebranche think we lack? 
Malebranche contrasts 'extension in itself' with 'the extension of bodies relative to each other' (OC I: 92/LO: 32) and 'absolute size' with relative sizes like 'large' and 'small', noting that 'nothing is either large or small in itself' (OC I: 9I/LO: $3 \mathrm{I}$ ). These contrasts suggest that the expressions 'extension in itself', 'true size', and 'absolute size' all refer to an intrinsic or nonrelational spatial property of bodies. Consider a palm tree. The palm tree is bigger than some things and smaller than others: bigger than a mite and smaller than a mountain. But it is not simply a brute fact that the palm tree stands in precisely these size relations: the palm tree has an intrinsic or nonrelational spatial property in virtue of which it is bigger than the mite and smaller than the mountain. Malebranche uses the term 'extension in itself' and similar expressions to refer to this kind of intrinsic spatial magnitude: the property in virtue of which an object is bigger or smaller than other things. Thompson (2016: 163), for example, describes this property as a 'metric independent spatial property', since metrics involve a comparison to a defined standard, for example, the standard meter stick. And Malebranche is saying that visual experience does not provide access to this property.

Our next question is how to specify the kind of access that Malebranche thinks we lack. Some passages suggest that the limitation is epistemic: that we cannot know extension in itself-that is, the nonrelational magnitude of things-just by looking. Alquié hints at a reading along these lines: 'there is a true size, which God alone perceives. Our senses do not teach us anything about true size' (Alquié I974: I74, emphasis added; see also Gueroult I959: 60). Visual experience might not provide knowledge of true or absolute size for many reasons, for instance, because it is insufficiently precise. Or perhaps sight fails to yield knowledge about extension in itself because it does not provide any certainty in this domain or because it does not accurately represent the intrinsic spatial magnitudes of objects.

Malebranche clearly accepts the epistemic limitation: namely, that we cannot know an object's absolute size just by looking. But this epistemic limitation is explained by a more fundamental restriction on the representational content of visual experience. We cannot know extension in itself on the basis of sight because sight does not represent objects as having any intrinsic or nonrelational magnitudes. Visual experience does not misrepresent the intrinsic or nonrelational magnitudes of objects; rather, visual experience is silent with respect to their intrinsic magnitudes. Many of the passages we saw above can be read as saying that we have no sensory access to the absolute sizes of objects, which suggests that Malebranche accepts the representational restriction as well as the epistemic one. He claims, for example, that 'we do not know how to determine the absolute size of the bodies surrounding us' (OC I: 86/LO: 28), and that 'our senses . . cannot tell us what bodies are in themselves' (OC I: I86/LO: 85). If sight were to represent objects as having intrinsic or nonrelational spatial magnitudes, then we would presumably have some kind of sensory access to these magnitudes, even if this access falls short of knowledge. But these passages suggest that our visual experience is completely cut off from the true or absolute sizes of things.

The texts canvassed so far might seem ambiguous between the epistemic and representational readings. In one passage, however, Malebranche says explicitly that the senses do not represent the absolute sizes of things: 'our sight does not 
represent extension to us as it in itself, but only as it is in relation to our body [Nôtre vîë ne nous représente donc point l'étenduë, selon ce qu'elle est en elle-même; mais seulement ce qu'elle est pas rapport à nôtre corps]' (OC I: 84/LO: 28, emphasis added). The representational language is significant: our sight does not represent (représente) the intrinsic or nonrelational magnitudes of objects. This is clear evidence that Malebranche accepts the representational restriction in addition to the epistemic one.

Assuming that size properties are absolute or relative, that is, nonrelational or relational, Malebranche's view that the visual experience of size does not represent absolute size implies that visual experience represents only relative size. Malebranche restricts the deliverances of sight even further. He claims that visual experience represents only size relative to the perceiver's body. That is the force of the second half of his claim that 'our sight does not represent extension to us as it is in itself, but only as it is in relation to our body' (OC I: $84 / \mathrm{LO}: 28$, emphasis added). A few pages later he reiterates that 'all we can know about the size of bodies by means of sight is the relation between them and our body [tout ce que nous en pouvons sçavoir par nôtre vî̈e, n'est que le rapport qui est entr'eux \& le nôtre]' (OC I: 88/LO: 30 , emphasis added). And he claims that our eyes 'perform their duty quite well by providing us with ideas of objects proportioned to the idea we have of the size of our body' (OC I: 87/LO: 29; see also OC I: I86/LO: 85, OC I: 92/LO: 32, and OC XVII: 268). Malebranche also hints at his body-relative view in claiming that sight measures distance in steps. In Elucidation $\mathrm{XV}$, for example, he writes: 'I open my eyes in the middle of the countryside and in an instant I see an infinity of objects. . . . Among other things I see at about a hundred steps from me a large white horse running toward the right at a great gallop' (OC III: $343-44 / \mathrm{LO}: 744-45$, emphasis added; see also OC XV: I6). Malebranche thus anticipates Bennett's body-relative approach to size perception (Bennett 20II; see also Thompson 20IO: I 55-59), as well as the psychological results Bennett draws upon, such as Warren (I984) and Warren and Whang (I987).

Let me preempt two possible misunderstandings. First, we might think that seeing the relations between one's own body and other material things requires prior awareness of the nonrelational properties of both. When a perceiver sees that a doorframe is bigger than her body, for example, we might assume that she has a sense of how big the doorframe is as well as a sense of her own body's dimensions and that she then notices the relation between them. That is the wrong way to think about Malebranche's view, however. Instead, Malebranche holds that our visual experience of the relations-of the ratios or comparisons-between our bodies and other material things is fundamental. When a perceiver sees that a door is big enough for her body to pass through, for example, she just sees 'the fit' between them. Still, we might wonder what kind of awareness we have of our own body's size. I argue elsewhere (Chamberlain, 2020) that both proprioception and vision provide information about the relative sizes of our own bodies. Visual experience represents how big our bodies are relative to external things, whereas proprioception represents how big our bodies are relative to their constituent parts. In effect, I argue that proprioception represents the way the body's parts are related to one another and to the whole. 
Second, we might think that sight represents precise comparisons to the perceiver's body, for example, that the palm tree is precisely three times larger than her body. But Malebranche holds that visual experience represents only approximate relations. 'It must not be imagined, however, that our senses correctly inform us of the relation that other bodies have to our own,' Malebranche argues, 'for exactitude and precision are not essential to sensory cognition [connoissances sensibles], which need serve only for the preservation of life' (OC I: 92/LO: 32, emphasis added). Consider, again, a perceiver approaching a door. There is some fact of the matter about precisely how much wider the doorframe is than the perceiver. The senses do not represent the exact ratio, but whether the perceiver can slip through.

Let us now turn to Malebranche's arguments for his view.

\section{Miniature and Giant Worlds}

As commentators like Bréhier (I938: I46), Gueroult (I959: 63), Alquié (I974: I77), and Simmons (2003 and 2008) emphasize, Malebranche holds that the senses 'were given to us for the preservation of the body' (OC I: 76/LO: 23; see also OC I: 376/LO: I95, OC II: I $30 / \mathrm{LO}: 339$, OC III: I $85 / \mathrm{LO}: 646-47$, OC XI: I46, and OC XII: $284 /$ JS: 222). The senses are not meant for metaphysics or abstract reasoning, but to help us survive. 'Our eyes are not given to us to discover the exact truths of geometry and physics', Malebranche argues, but rather 'to clarify all the movements of our body in relation to those surrounding us, and simply for the convenience and preservation of life' (OC XII: II 9-2O/JS: 80). The biological function of the senses constrains the kinds of properties they represent: the senses 'speak only for the preservation of life' (OC XII: I I9/JS: 80, emphasis added). The senses do not represent the 'exact configuration of the parts of some fruit', for example, but whether the fruit is nourishing or good to eat (OC I: 74/LO: 22).

Malebranche sometimes argues that visual experience represents only body-relative size by appealing to the biological function of the senses:

It is a groundless prejudice to believe that we see material things as they are in themselves. For our eyes, which were given to us only for the preservation of our body, perform their duty quite well by providing us with ideas of objects proportioned to the idea we have of the size of our body. (OC I: 87/LO: 29)

For the purposes of interacting with objects, absolute size is irrelevant: only body-relative size matters. To get through a doorframe, it helps to see that you will fit through. To pick up a mug, it helps to see that the mug will fit in your hand. Seeing the doorframe or the mug as having some nonrelational or intrinsic magnitude does not yield any practical advantage. Since visual experience represents only what matters for survival, visual experience represents only body-relative size.

Malebranche's most explicit argument for the body-relativity of visual size, however, appeals to perceptual variation. He illustrates the possibility of radical 
perceptual variation with respect to size using two thought experiments. Here is the first one:

But to better understand what we should judge concerning the extension of bodies on the basis of the testimony of our senses, let us imagine that from a quantity of matter the volume of a ball God has made a miniature earth and sky, and men upon this earth having the same proportions observed in the larger world. These tiny men would see one another, the parts of their bodies, and even the little animals that might bother them, for otherwise their eyes would be useless for their preservation. It is obvious on this supposition, then, that these tiny men would have ideas of the size of objects quite different from ours, since they would regard their world, which is but a ball to us, as having infinite space, more or less as we judge the world we are in. (OC I: 87-88/LO: 29, emphasis added; see also OC I: $84 / \mathrm{LO}: 28$ )

Malebranche imagines a miniature world filled with miniature people, apparently inspiring Swift's Gulliver Travels and Voltaire's Micromegas (see, e.g., Gueroult I959: 57n.52, and Alquié r974: I74). We might find Malebranche's conclusion that 'these tiny men would have ideas of the size of objects quite different from ours' counterintuitive. After all, their palm trees and their blades of grass look to them as our palm trees and grass look to us. From the point of view of the perceivers, the two worlds are observationally indistinguishable. But, as Simmons (2003: 402) has emphasized, Malebranche's conclusion is about the visual experiences that perceivers from these two worlds would have regarding one and the same object-like a palm tree from our world or a blade of grass from the miniature world-rather than the numerically distinct but duplicated objects in the two distinct worlds. When looking at a palm tree from our world, a typical human and a perceiver from the miniature world would indeed represent the palm as having very different sizes. Their world looks enormous to them, but small to us. The miniature people would see a speck of dust from our world as gargantuan, whereas we see that same speck as, well, a speck. While those of us familiar with the I980's classic Honey I Shrunk the Kids might find this perceptual variation intuitive, Malebranche defends the plausibility of his conclusion by arguing that if a miniature world is possible, then its inhabitants will perceive a given object as having a different size than we do because 'otherwise their eyes would be useless for their preservation' (OC I: 87/LO: 29).

Imagining the microscopic world may be difficult, since 'the imagination loses itself and wonders at the sight of extreme smallness' (OC I: 80/LO: 26). This leads Malebranche to propose a second thought experiment:

Or, if it is easier to conceive, suppose that God created an earth infinitely more vast than the one we inhabit, such that this other world would stand to ours as ours stood to the one we were just speaking about in the preceding supposition. In addition to this, let us suppose that God preserved among all the parts composing this other world the same 
proportion as among the parts composing ours. It is clear that the men of this other world would be larger than the space between our earth and the most distant stars we see; this being so, it can be seen that if they had the same ideas of the extension of bodies as we have, they would be unable to discern certain parts of their own body, while they would see certain others as having an enormous bulk. As a result, it is ridiculous to suppose that they see things as having the same size as we see them. (OC I: 88/LO: 29-30)

Malebranche again concludes that when presented with a numerically identical object, the giant people will represent it visually as having a very different size than our visual experience represents it to have. Everest is a speck to them, but a mountain to us.

These thought experiments show that differently sized perceivers might see the same objects—such as a palm tree from our world-as having very different sizes even when they are in good perceptual conditions and their visual systems are functioning well. A miniature person sees the palm tree as enormous, a typical human being sees this palm tree as moderately sized, and a giant sees it as vanishingly tiny. As Malebranche writes, 'it is obvious from these two suppositions we have just made that the men of the larger or smaller world would have ideas of the size of bodies quite different from our own' (OC I: 88/LO: 30 ). Malebranche then moves from 'these two suppositions' to the conclusion 'that all we can know of size through sight is the relation between them and our body, a relation by no means exact' (OC I: 88/LO: 30 ). Unpacking this move is the key to Malebranche's argument. In the next section, I will criticize Atherton's (I990) and Simmons's (2003) accounts of this inference, before presenting my alternative.

\section{Atherton's and Simmons's Reconstructions}

Atherton (I990) reads Malebranche as presenting the following short argument: different perceivers have visual experiences that represent the same objects as having different sizes; therefore, visual experience 'leaves us in no position to make claims about the absolute size of anything in the physical world' (Atherton I990: I32). Rather, visual experiences 'express at best the size an object is relative to our bodies' (Atherton I990: I3 I; see also 36-37 and I30). Atherton's reconstruction moves from the possibility of perceptual variation to the conclusion that visual experience represents only body-relative size without any intermediate premises. This rendition of the argument goes too fast, however. Different perceivers-or the same perceiver at different times and in different circumstances-might experience the same objects as having different sizes, shapes, or colors. But this kind of perceptual variation does not immediately entail that the experienced properties are relational, let alone relative to the body. Suppose, for example, that someone sees a tower as square up close and as round in the distance. It does not thereby follow that this person's visual experience represents the tower's squareness and roundness as relational properties, at least not without further argument. And 
similarly for size. Hence, Atherton's reconstruction needs to be supplemented with additional premises to yield Malebranche's conclusion.

Simmons (2003) suggests one way of filling in the details. On her reading, the view that visual experience represents only body-relative size provides the best explanation for the perceptual variation. Here she is in her own words:

The mini-earth that we regard as 'but the size of a ball', the mini-people
regard as having 'infinite space'. The difference in perceived size cannot
be explained solely by the fact that the mini-world occupies more visual
angle for the mini-people than it does for us, for Malebranche recognizes
that the visual angle underdetermines the perceived size of objects. What
distinguishes the size perceptions of the mini-people and us is the
difference in size relative to our differently sized bodies. This relativity
in size perception seems to underlie Malebranche's warning that 'we
are very uncertain about the true size of the bodies we see, and all we
can know of it by sight is the relation between their size and our own'.
(Simmons $2003: 402$, emphasis added)

Simmons presents Malebranche as making an argument to the best explanation. The phenomenon to be explained is that perceivers of different sizes (namely, mini-people, giant-people, and ordinary human beings) see the same objects as having different sizes even when these perceivers are in good perceptual conditions and their visual systems are functioning well. The best explanation of this phenomenon, Simmons proposes on Malebranche's behalf, is that the differences in visual experiences of size track, or covary with, differences in the way that perceivers' bodies are related to the objects they see. As Simmons writes, 'what distinguishes the size perceptions of the mini-people and us is the difference in size relative to our differently sized bodies' (Simmons 2003: 402). This co-variation is intended to support the conclusion that 'sensory representation of size . . . is scaled to the perceiver's body size' (Simmons 2003: 402).

There are two problems with Simmons's reconstruction. First, the argument moves from the premise that (i) differences in the visual experiences of size track, or covary with, differences in the way that perceivers' bodies are related to the objects they see to the conclusion that (ii) visual experience represents only body-relative size. This transition depends on a suppressed premise that visual experience represents the properties it tracks or co-varies with. But Malebranche generally rejects any tight connection between representation and tracking. Our experiences of objects as colored-that is, as red, green, blue, and so forth-track microscopic surface structures of bodies. But, Malebranche insists, these color experiences do not represent the relevant microscopic structures, as Simmons (2008) herself notes (see, for example, OC I: 73/LO: 2I, OC I: I27-28/LO: 5I52, OC I: $385 / \mathrm{LO}: 200$, OC XII: Ioo/JS: 63, and OC XII: I04/JS: 67). Thus, Simmons's reconstruction leaves open the possibility that visual experiences track but do not represent the body-relative sizes of objects. Second, Simmons's reconstruction omits a premise that Malebranche suggests is crucial: namely, that there is no principled and well-motivated reason for singling out one way of seeing 
the palm tree's size as better than the others. (Atherton's reconstruction omits this premise as well.) Adding this premise allows Malebranche to argue that the differently sized perceivers represent and do not merely track size-in-relation-to-their-body. And this brings us to the next section.

\section{Veridical Perceptual Variation}

Immediately after presenting his thought experiments, Malebranche observes that any of these perceivers would be mistaken if they took their visual experience to reveal the true sizes of objects. He writes: 'If these men relied heavily on the testimony of their eyes that objects are such as they see them, it is clear that they would be mistaken; nobody can doubt this' (OC I: 88/LO: 30). Each of the differently sized perceivers has an equally good claim to experience the palm tree's size veridically: 'Nonetheless, these men would certainly have as much reason as we to defend their opinion' (OC I: 88/LO: 30). In other words, there is no principled reason to single out one way of experiencing the palm tree's size over the others. Neither Atherton (I990) nor Simmons (2003) incorporate this premise in their reconstructions. Yet from this Malebranche concludes that sight is restricted to representing body-relative size. As Malebranche writes: 'Let us learn, then, by their example that we are quite uncertain of the true size of the bodies we see, and that all we can know of size through sight is the relation between them and our body, a relation by no means exact' (OC I: 88/LO: 30). That is, Malebranche argues as follows:

(I) Differently sized perceivers-such as a miniature person, a typical human being, or a giant-can have visual experiences representing a single object—such as a palm tree-as having radically different sizes even when they are in good perceptual conditions and their visual systems are working normally.

(2) There is no principled reason to privilege one of these ways of experiencing the palm tree's size as uniquely veridical, and, hence, there is no uniquely veridical way of experiencing the palm tree's size. Either all these ways of experiencing are veridical or none are.

(3) But it is implausible that none are veridical.

Therefore,

(4) All these different ways of experiencing the palm tree's size are veridical. (From 2 and 3 )

(5) The best explanation for how these different ways of experiencing the palm tree's size-miniature, typical human being, and giantcould all be veridical yet different is that visual experience represents only body-relative size.

Therefore,

(6) Visual experience represents only body-relative size. (From I, 4, and 5).

Atherton's Malebranche leaps from (I) directly to (6). Simmons's Malebranche includes a version of premise $(5)$ to indicate an inference to the best explanation 
but does not specify that what needs to be explained is not just variation in experiences of size, but variation in veridical experiences of size-as established by (2) and (3). Neither Atherton nor Simmons recognize that Malebranche's argument hinges on (2): the assumption that there is no reason to privilege one way of experiencing the palm tree's size over the others, and so they do not appreciate the argument's force. This style of argument-which appeals to the possibility of veridical perceptual variation-is standardly used to argue that we experience color in relational terms (see, for example, Cohen 2009: 24). Malebranche shows that a similar strategy can be applied to the experience of size.

Simmons's reconstruction has the right general shape. I agree with Simmons that Malebranche offers an argument to the best explanation. But she mischaracterizes the phenomenon to be explained. The explanandum is not merely perceptual variation, but veridical perceptual variation. This difference is crucial. Focusing on the fact that the different ways of seeing the palm tree's size are equally veridical provides traction on their representational content because whether an experience is veridical in a certain situation depends, of course, on what the experience represents.

Let us now work through my reconstruction more slowly. Premise (I) falls out of Malebranche's thought experiments. Malebranche commits himself to premise (2) when he observes that both the miniature person and the giant person 'have as much reason as we to defend' their ways of seeing the palm tree's size (OC I: 88/ LO: 30 , emphasis added). This suggests that we should not privilege one way of experiencing the palm tree's size at the expense of the others and, hence, that there is no uniquely veridical way of experiencing the palm tree's size. If there were, it would be an unappealing brute fact that the giant, say, veridically represents the palm tree's size, whereas the miniature person and the typical human being systematically misrepresent the sizes of things even when they are in good perceptual conditions and their visual apparatuses are working well. Privileging the giant's way of seeing things would be tantamount to saying that being a miniature person or a typical human being just is a bad perceptual condition, which seems wrong. From this it follows that there is parity between the different ways of experiencing the palm tree's size. Either all three ways of experiencing the palm tree's size are veridical or none of them are.

Premise (3) points out that it is implausible that all three ways of experiencing the palm tree's size are nonveridical. Suppose, for reductio, that the miniature person, the typical human being, and the giant all misrepresent the palm tree. Because the possibility of perceptual variation is rampant-for any given object, we can imagine how it might look to a miniature person or a giant-we would then be forced to the conclusion that no visual experience of size is ever veridical. This would be a thoroughgoing error theory about the visual experience of size. This result flies in the face of common sense, however, and is one Malebranche would be unhappy with.

Although Malebranche often suggests that our sensory experience of sensible qualities-for example, our experience of objects as colorful, smelly, tasty, and so forth-systematically misrepresents the nature of material things, he is more optimistic about the spatial aspects of visual experience. In Search I.Io, he 
summarizes his discussion of spatial perception by saying that 'the judgments we form on the testimony of our eyes concerning extension, figure, and motion are never exactly true. Nevertheless, it must be agreed that they are not altogether false', a point he reiterates a few paragraphs down: 'the judgments we make concerning extension, figure, and motion of bodies include some measure of truth' (OC I: I2I-22/LO: 48, emphasis added). This passage suggests that visual experience sometimes veridically represents size or extension. Indeed, Malebranche argues that 'our senses are very faithful and exact' (OC I: I 86/LO: 85 ) and are 'faithful witnesses'; that is, they speak truly 'in respect of what concerns the good of the body and the preservation of life' (OC XII: 30/JS: 4). 'The senses are very useful', Malebranche writes, 'in knowing [connaitre] the relations external bodies have to our own' (OC I: 488/LO: 26I, emphasis added).

Moreover, Malebranche might argue that visual experience does not systematically misrepresent size on the grounds that a benevolent, nondeceiving God designed our visual systems. This appeal to God's benevolent, non-deceiving nature is delicate, however, as Malebranche takes God's nature to be compatible with systematic sensory misrepresentation in the case of sensible qualities. Malebranche might defend treating spatial and sensible qualities differently by appealing to the fact our intellectual understanding of the nature of matter reveals that material things have spatial properties, whereas they lack sensible qualities (OC III: I64-66/LO: 633-35). Thus, Malebranche can argue that God's benevolent, non-deceiving nature always creates a presumption against systematic misrepresentation within a given sensory domain although this presumption can be overcome by our intellectual understanding of matter, as is the case for sensible qualities.

Now, someone might object to my attribution of (3) to Malebranche on the grounds that he claims that the different sized perceivers would be 'mistaken' to rely on their respective experiences of size: 'If these men relied heavily on the testimony of their eyes that objects are such as they see them, it is clear that they would be mistaken; nobody can doubt this' (OC I: 88/LO: 30 ). But this passage does not say that the perceivers' respective experiences are non-veridical or misrepresent. Rather, different sized perceivers would be making an error if they interpret their experiences as providing them insight into what objects are reallythat is, intrinsically or nonrelationally-like. In other words, Malebranche locates this mistake at the level of the will or free judgment, rather than experience or natural judgment. This passage thus leaves open the possibility that the differently sized perceivers experience the palm tree's size veridically.

Premise (4) draws out the implications of (2) and (3). If the different ways of experiencing the palm tree's size-miniature, typical human, and giant-enjoy parity such that either all of them are veridical or none of them is, and we reject the possibility that they are all nonveridical, then it follows that all three ways of seeing the palm tree's size are veridical. We then get a phenomenon that calls out for explanation: how all three perceivers can experience one and the same palm tree as having wildly different sizes, and yet all three experience the palm tree's size veridically. 
Premise (5) claims that the best explanation for this phenomenon-of veridical perceptual variation-is that visual experience represents only body-relative size because the palm tree is enormous compared to the miniature perceiver's body, small compared to the giant's, and so forth. Malebranche does not explicitly articulate this premise. But the logic of his argument requires it. This leads to the conclusion that visual experience is restricted to representing body-relative size.

Malebranche's thought experiments may seem fanciful. But he is pointing to a familiar kind of experience. Although we will probably never get to see the world from a microscopic perspective, we have all occupied the perspectives of the children we once were. I remember my childhood home as a vast kingdom and my parents as giants. When I go home as an adult, everything seems smaller, and my parents have shrunk. But I am the one who has changed, not they, and it would be a mistake, says Malebranche, to elevate the adult's perspective over the child's.

\section{A Strange View?}

Someone might object that my reading attributes a strange view to Malebranche. The apparent strangeness of the view might lead us to worry about the correctness of the attribution as well as about the philosophical tenability of the view itself. In this section, I will address three versions of the strangeness objection. First, we might worry that Malebranche's body-relative view conflicts with the seemingly obvious fact that we sometimes see objects as bigger or smaller relative to one another. When two people stand back to back, for example, we can see that one person is taller than the other. But their relative height does not seem to involve the perceiver's body as a relatum. Malebranche alludes to this type of case. As Malebranche writes, visual experience represents 'the extension of bodies in relation to each other', and he observes that 'the same moon appears to us as much larger than the largest of the stars' (OC I: 92/LO: 32; see also OC XVII: 264).

In response to this objection, we should note that Malebranche's view is ambiguous as stated thus far. On the one hand, he could hold that visual experience represents only two-place size relations, like bigger than or smaller than, such that these two-place relations invariably include the perceiver's body as a relatum. This version of the view would indeed imply that we do not see one person as taller than the other or that the moon is bigger than the stars. On the other hand, Malebranche could hold that visual experience represents only $n$-place size relations that always include the perceiver's body as one of the relata. The former option implies that visual experience only compares objects to the perceiver's body, whereas the latter implies that visual experience always compares objects to the perceiver's body while leaving open the possibility of other visual comparisons. My proposal is that we should read Malebranche as endorsing the second option because it reconciles the body-relativity of visual size with the phenomenological datum that we see objects as bigger or smaller than others.

When the moon looks bigger than the largest of stars, for example, we see that the moon is small whereas we see the stars as specks. But whether something is small or a speck depends on its size relative to our body. Our body is the metric here. The second option can accommodate this observation by arguing that visual 
experience represents a three-way comparison of the relative sizes of the moon, the star, and the perceiver's body. This three-way relation includes the perceiver's body as a relatum and, hence, is compatible with the claim that visual experience represents $n$-place size relations involving the perceiver's body. As Malebranche writes, 'we can sometimes judge through sight the approximate relation bodies have to our own as well as among themselves' (OC I: 92/LO: 32, emphasis added). He echoes this claim in his polemic with Regis, suggesting that the 'short means of sensation' informs us about 'the relations which are among bodies, and with the one we animate' (OC XVII: 268). Thus, Malebranche can allow that we see the size of objects in relation to each other so long as our experience of their relation also includes a comparison to the perceiver's body.

Moreover, Malebranche's biological conception of the senses predicts that visual experience will always compare objects to the perceiver's body. Suppose, for example, that someone wants to roast a chicken. She is standing in the kitchen, the chicken is on the counter, and she needs to get it into the oven. If this person were to see how big the chicken is vis-à-vis the oven, without also telling the perceiver anything about how she compares to the chicken and oven, she would be at a loss about how to proceed in this situation. Maybe the perceiver is a mini-person or a giant who has been transported to our world and is suddenly confronted by a chicken and oven from our world for the first time. Without some sense of how she relates to objects, she won't know how to interact with them. Should she pick the chicken up and put it in the oven using a magnifying glass and a pair of tweezers, if she is a giant, or establish a settlement next to the chicken and start mining chicken flesh, if she is miniature? The moral of this example is that knowing how big or small objects are in relation to one another is useful or actionable only if you also have some sense of how you fit into the situation. More specifically, visual information about the relative sizes of external objects is useful for action only if visual experience also compares these objects to the size of the perceiver's body. Hence, the biological function of the senses suggests that the visual experience of size always, but not necessarily only, involves a comparison to the perceiver's body: 'for otherwise [her] eyes would be useless for [her] preservation' (OC I: 87/LO: 29).

Second, we might object to Malebranche's view on the grounds that size just does not look relational. This style of objection is familiar from debates in the philosophy of color, where philosophers object to dispositional analyses of color on the grounds that color (supposedly) does not look relational either. As McGinn writes:

When we see an object as red we see it as having a simple, monadic, local property of the object's surface. The color is perceived as intrinsic to the object, in much the way that shape and size are perceived as intrinsic. No relation to perceivers enters into how the color appears; the color is perceived as wholly on the object, not as somehow straddling the gap between it and the perceiver. Being seen as red is not like being seen as larger than or to the left of. The 'color envelope' that delimits an object stops at the object's spatial boundaries. (McGinn I996: 54 I-42) 
McGinn takes it for granted that we perceive size as intrinsic and tries to motivate the corresponding claim about color. But we can borrow some of his language to help motivate the intuition about size as well: when we see an object as having a certain size, we see it as having a simple, monadic, local property. The size is perceived as intrinsic to the object, in much the same way that shape and color are perceived as intrinsic. No relation to perceivers or their bodies enters into how the size appears; the size is perceived as wholly in the object, not as somehow straddling the gap between it and the perceiver. This description of the contents of size perception, if correct, would be bad news for Malebranche.

This objection assumes that the metaphysical structure of the properties represented in visual experience-whether they are absolute, relational, etc.-is obvious or transparent in visual experience itself. But Malebranche rejects this assumption. Malebranche holds that it takes hard work to discern the precise contents of sensory experience. He alludes to the opacity of sensory experience in the Dialogues on Metaphysics and Religion, for example, when he writes that the 'testimony of the senses' is devoid of 'precision' (OC XII: 30/JS: 4), 'full of darkness' (OCM XII: 65/JS: 33), and 'obscure and confused' (OCM XII: 75/JS: 4I). In the Search, he argues that the deliverances of the senses are 'confused' (OCM I: 72/LO: 2I), 'false or obscure' (OCM I: 376/LO: I95), and 'not clear' (OCM III: 72/LO: 580). And in the Christian Meditations, the meditator finds himself 'in a strange muddle' when he tries to 'make a serious reflection' on what his senses tell him (OC X: 47). Thus, Malebranche can argue that the fact that we see body-relative size is not obvious, transparent, or infallibly known via introspection.

Writing in a present-day context, Shoemaker makes a similar point: 'the way properties are represented in our experience is no reliable guide to what the status —as monadic, dyadic, etc.- - of these properties is' (Shoemaker I994: 28). More generally, sensory experience can represent a property without thereby disclosing the true nature of that property. We might see a clear liquid as water, for example, without thereby seeing it as $\mathrm{H}_{2} \mathrm{O}$.

Moreover, Malebranche can argue that the temptation to describe our size experience in absolute or nonrelational terms is an illusion generated at the level of free judgment. In his discussion of the beauty of insects, Malebranche argues that people often draw unwarranted conclusions about the absolute sizes of things from their visual experiences of body-relative size. As Malebranche writes, 'because these animals are small in relation to our bodies, vision makes us consider them as absolutely small' (OC I: 9I/LO: $3 \mathrm{I}$ ). Malebranche might then explain the temptation to describe the visual experience of size in absolute terms by appealing to our tendency to confuse natural and free judgments. Suppose, for example, that someone looks at an insect. Her visual experience represents the insect as small relative to her body. On the basis of this experience, she mistakenly forms a free judgment attributing an absolute size to the insect. She might then mistakenly believe that her visual experience represents absolute size because she fails to distinguish her free judgment from the sensory experience on which it is (loosely) based. As Pyle cautions, 'we need . . . to distinguish carefully between what is actually presented to the senses, and what is added by the mind of the 
observer, and may be the result of mere habit or prejudice, albeit a prejudice that comes naturally to us' (Pyle 2003: 99).

On my reading, then, Malebranche rejects 'Content Cartesianism, where one knows indubitably that one has a certain sort of thought with a certain content' (Schmaltz 1996: 22, second emphasis added). As Schmaltz himself points out, there are reasons to doubt that 'Content Cartesianism' represents Malebranche's considered view, as Malebranche describes a number of counterexamples (Schmaltz I996: 22-23). Schmaltz mentions Malebranche's claim that 'people can have an agreeable sensation and yet not know it to be agreeable' (Schmaltz I996: 2I). Malebranche also holds that 'it sometimes happens that we have so many different thoughts that we imagine we are thinking about nothing at all' and that 'these people sense so many things at once that they sense nothing distinct, which makes them imagine that they have sensed nothing' (OC I: 39I/LO: 203). If people can fail to recognize that they are sensing something rather than nothing, presumably they can fail to recognize that they are sensing a relational property rather than a nonrelational one. Many commentators-like Schmaltz (I996), Moriarty (2003), and Nolan and Whipple (2005)—emphasize that Malebranche rejects the Cartesian view that we have a clear and distinct grasp of the fundamental nature of the mind. Malebranche's suspicion about self-knowledge is also expressed in his denial that knowing the contents of our sensory experiences is easy, that is, in his denial that we can know these contents through a cursory inward glance. It is not only the depths of our minds that are hidden from us. The surfaces can elude us too.

Third, someone might object that Malebranche cannot explain why people mistakenly draw conclusions about the absolute sizes of things from their visual experiences of body-relative size. This objection is especially pressing for Malebranche given his view-which he shares with Descartes—that free judgment or belief consists in the will's assent to a perception, such that the judgment inherits its content from the perception (OC I: 49-50/LO: 7-8). If people form judgments about absolute or intrinsic size, then the contents of these judgments have got to come from somewhere. But Malebranche cannot appeal to the visual basis for these judgments as the source of their contents, given his view that sight does not represent absolute size.

In response to the last part of this objection, Malebranche can argue that we have an intellectual idea of absolute size that we mistakenly impose on the deliverances of visual experience, but that is strictly foreign to the content of this experience. When someone looks at an insect, for example, she sees the insect as small relative to her body. This visual experience is then botched together with an intellectual idea of absolute size, where the resulting hybrid mental state provides the content for her free judgment that the insect is absolutely small. Still, we do not yet have an explanation of why visual experience might dispose us to make this mistake. What about our experience of the insect as small relative to our body invites us to judge that the insect is absolutely small? Malebranche appeals to our tendency to treat our body as an 'absolute measure'-that is, to treat body-relative properties as if they were absolute or nonrelational properties of things (OC I: 9I/LO: $3 \mathrm{I}$ ) - to explain why we habitually make the transition from body-relative to absolute size. 
We might worry that Malebranche has not really given much of an explanation here: that merely appealing to this tendency is a placeholder rather than a proper account. And it would be nice if Malebranche analyzed this tendency-perhaps in terms of the associative powers of the imagination or as an expression of human self-centeredness or pride. But he could also reasonably treat this tendency as a basic feature of the human mind. This last objection, then, is not a devastating problem for Malebranche.

\section{Conclusion}

I have argued that Malebranche holds that the visual experience of size represents only body-relative size. More specifically, the visual experience of an object's size always involves a comparison to one's own body. Although material things presumably have intrinsic or nonrelational magnitudes, visual experience is silent about them. I have also argued that Malebranche's central argument for this thesis is more sophisticated than other commentators have appreciated. He does not make a mere appeal to the perceptual variability of size, pace Atherton (I990), nor does he presuppose that visual experience represents the properties it tracks, pace Simmons (2003). Rather, Malebranche's argument hinges on a premise about the veridicality of various experiences of size, which allows him to draw conclusions about the representational content of these experiences.

Malebranche can also defend his view against the charge of phenomenological implausibility. Part of this defense is to emphasize that the contents of visual experience are not obvious to introspection. Figuring out what we are seeing requires more than a cursory inward glance. It is hard work. The demotion of introspection helps explain why Malebranche appeals to our intuitions about the veridicality conditions of different kinds of visual experience to establish his body-relative account. If a cursory inward glance does not reveal the representational content of visual experience, then some other technique or strategy is required. Malebranche's thought experiments about miniature and giant worlds are one such technique. Thus, Malebranche illustrates the possibility of investigating the contents of experience without getting mired in intractable debates where divergent introspective reports are pitted against one another.

COLIN CHAMBERLAIN

TEMPLE UNIVERSITY

colin.chamberlain@temple.edu

\section{References}

Alquié, Ferdinand. (1974) Le cartésianisme de Malebranche. Paris: J. Vrin. Atherton, Margaret. (I990) Berkeley's Revolution in Vision. Ithaca, NY: Cornell University Press. Bennett, David J. (20II) 'How the World Is Measured Up in Size Experience'. Philosophy and Phenomenological Research, 83, 345-65.

Bréhier, Émile. (1938) 'Les « jugements naturels » chez Malebranche'. Révue Philosophique de la France et de l'Étranger, I25, I42-50. 
Chamberlain, Colin. (2020) 'Our Body is the Measure: Malebranche on the Body-Relativity of Sensory Perception'. Oxford Studies in Early Modern Philosophy, IX, 37-74.

Cohen, Jonathan. (2009) The Red and the Real: An Essay On Color Ontology. Oxford: Oxford University Press.

Gueroult, Martial. (1959) Malebranche: Les cinq abimes de la providence. 3 vols. Vol. 3. Paris: Aubier.

Jolley, Nicholas. (I995) 'Sensation, Intentionality and Animal Consciousness: Malebranche's Theory of Mind'. Ratio, 7, I28-42.

Malebranche, Nicolas. (1958) Oeuvres complètes. Paris: J. Vrin.

Malebranche, Nicolas. (I997a) The Search After Truth. Translated by Thomas M. Lennon and Paul J. Olscamp. Cambridge: Cambridge University Press.

Malebranche, Nicolas. (1997b) Dialogues on Metaphysics and on Religion. Translated by Nicholas Jolley and David Scott. Cambridge: Cambridge University Press.

McCracken, Charles. ( $\mathrm{I}^{9} \mathrm{8}_{3}$ ) Malebranche and British Philosophy. Oxford: Oxford University Press.

McGinn, Colin. (I996) 'Another Look at Color'. Journal of Philosophy, 93, 537-53.

Moriarty, Michael. (2003) Early Modern French Thought: The Age of Suspicion. Oxford: Oxford University Press.

Nadler, Steven. (I992) Malebranche and Ideas. Oxford: Oxford University Press.

Nolan, Lawrence, and John Whipple. (2005) 'Self-Knowledge in Descartes and Malebranche'. Journal of the History of Philosophy, 43, 55-8 I.

Pyle, Andrew. (2003) Malebranche. London: Routledge.

Radner, Daisie. (1978) Malebranche: A Study of a Cartesian System. Assen and Amsterdam: Van Gorcum.

Reid, Jasper. (2003) 'Malebranche on Intelligible Extension'. British Journal for the History of Philosophy, I I, 58 I-608.

Rodis-Lewis, Geneviève. (1963) Nicolas Malebranche. Paris: Presses Universitaires de France.

Rome, Beatrice. (1963) The Philosophy of Malebranche. Chicago: Henry Regnery.

Schmaltz, Tad. (I996) Malebranche's Theory of the Soul: A Cartesian Interpretation. Oxford: Oxford University Press.

Shoemaker, Sydney. (I994) 'Phenomenal Character'. Nous, 28, 2I-38.

Simmons, Alison. (2003) 'Spatial Perception from a Cartesian Point of View'. Philosophical Topics, $3 \mathrm{I}, 395-423$.

Simmons, Alison. (2008) 'Guarding the Body: A Cartesian Phenomenology of Perception'. In Paul Hoffman and Gideon Yaffe (eds.), Contemporary Perspectives on Early Modern Philosophy: Essays in Honor Vere Chappell (Peterborough, Canada: Broadview Press), 8 I-I I 3.

Simmons, Alison. (2009) 'Sensation in the Malebranchean Mind'. In Jon Miller (ed.), Topics in Early Modern Theories of Mind (Netherlands: Springer Press), I05-I 29.

Thompson, Brad. (20I0) 'The Spatial Content of Experience'. Philosophy and Phenomenological Research, 8I, I46-84.

Warren, William. (1984) 'Perceiving Affordances: Visual Guidance of Stair Climbing'. Journal of Experimental Psychology: Human Perception and Performance, Io, 683-703.

Warren, William, and Suzanne Whang. (1987) 'Visual Guidance of Walking Through Apertures: Body-Scaled Information for Affordances'. Journal of Experimental Psychology: Human Perception and Performance, $\mathrm{I}_{3}, 37 \mathrm{I}-83$.

Watson, Richard. (I966) The Downfall of Cartesianism, I673-I7I2: A Study of Epistemological Issues in Late I7th Century Cartesianism. The Hague: Martinus Nijhoff. 